\title{
PARA FORMAR PROFESSORAS E MÃES FORTES NO SERTÃO: AS DISCIPLINAS PUERICULTURA E HYGIENE NA ESCOLA NORMAL DE FEIRA -1938-1946
}

PALAVRAS-CHAVES: Higiene e Puericultura, Escola Normal, Feira de Santana.

\section{INTRODUÇÃO}

Este trabalho é parte integrante do Projeto "Escolarização e Formação Profissional em Feira de Santana a Escola Normal da Feira e o Colégio Santanopólis- 1909 / 1960" coordenado pela $\operatorname{Prof}^{\mathrm{a}} \mathrm{Dr}^{\mathrm{a}}$ Ione Sousa.

Ele procura investigar os saberes escolares que constituíam as disciplinas de Puericultura e Hygiene Escholar, entre os anos de 1938 a 1946, e delinear as relações de poder e a influência do discurso médico higienista no processo de ensino entre as normalistas enquanto futuras mães biológicas ou mães sociais representação do ser professora, numa perspectiva de sanitarização da infância e da Nação.

Vale lembrar que naquele período no Brasil em geral, inclusive nas cidades de médio porte como era Feira de Santana, a educação escolar normal era uma estratégia para dispersão do ideário da modernidade, civilidade no seu cotidiano. A Escola, especificamente nesta cidade, teria um papel “civilizador” que permitiria a difusão cultural e social às regiões circunvizinhas de um pretendido progresso regional.

\section{MATERIAL, MÉTODOS OU METODOLOGIA}

A pesquisa sobre as disciplinas de Puericultura e Hygiene na formação das normalistas na Escola Normal da Feira de Santana, enquanto integrante do projeto da professoraorientadora desta proposta, tem como base o manuseio dos registros e documentos desta antiga instituição (Escola Normal de Feira de Santana) que se acham no Instituto de Educação Gastão Guimarães (IEGG).

Quanto aos procedimentos de pesquisa, foi realizada a identificação, triagem, higienização e limpeza dos documentos, separando-os por ano e turma. Em seguida, foi executada a digitalização e leitura dos documentos, em busca de evidências quanto às práticas e saberes escolares referentes às disciplinas investigadas- Hygiene e Puericultura.

Dentre os documentos que fazem parte do acervo sob a guarda do IEGG encontram-se fichas de inscrição, decretos, livros didáticos, diários de classes. Outro acervo pesquisado é o que se encontra abrigado no Museu Casa do Sertão, constituído de jornais regionais. A análise da fonte oral, a entrevista com o um professor Dr. Péricles Ramos - médico pediatra - se tornou fundamental para prosseguimento da pesquisa.

No exercício de reflexão sobre estas evidências, articulei a historiografia da História da Educação com algumas questões sobre História Política. Veiga (2003) argumenta sobre a importância desta discussão para apreender as decisões normatizadoras que incidem nas escolas, enquanto ligadas as decisões políticas de uma época e local, assim como permite analisar o que a sociedade almejava naquele momento a partir da Educação.

\section{RESULTADOS E/OU DISCUSSÃO}

Quanto a discussão desenvolvida foram incorporadas categorias e conceitos como relações de poder e práticas políticas para analisar os Regulamentos da educação baiana do período, o que possibilitou apreender e criticar analiticamente estes registros como emanados de uma época. Analisar textos oficiais sobre a educação é lembrar o quanto tais produções são 
históricas e politicamente datadas, produzidos em razão das relações de poder e produtoras de saberes específicos.

Faria Filho ao tratar de regulamentos e leis como fontes para uma história da educação ressalta que um sujeito ou grupo ao enunciar um Regulamento espera o seu cumprimento e a obediência ao mesmo em prol do que está inscrito e prescrito nesta Lei. Assim, as práticas discursivas escolares, ou da escola, cumprem um comando preliminar enraizado pelas regras que a conceberam uma formação específica de uma clientela.

Esses Regulamentos apresentaram um pouco da estrutura administrativa, no que se refere aos atributos e funções do Diretor Geral de uma instituição escolar, dos Inspetores, dos/as professores/as, Delegados etc; da modalidade de ensino, como infantil, primário elementar, primário superior, complementar, normal, etc; da organização do espaço, como a localização do prédio das aulas e da instalação das escolas anexas etc; das condições materiais para o ensino gratuito; dos programas referentes à escola normal da capital e às escolas normais do interior. Enfim, da escola no período trabalhado como instituição capaz de elevar os indivíduos culturalmente de acordo o progresso, principalmente quanto combatem o analphabetismo.

Supondo, assim, que em toda sociedade há um conjunto de procedimentos externos que a organize, utilizei de Foucault sobre a relação entre quem produz o discurso e qual seu objetivo. Dessa forma ele diz que:

“(...) a produção do discurso é ao mesmo tempo controlada, selecionada, organizada e redistribuída por números de procedimentos que tem por função conjurar seus poderes e perigos, dominar o seu acontecimento aleatório, esquivar sua pesada e temível materialidade” (1996, p. 8-9)

A atuação do Estado, por meio da Educação, não fugiria dos ideais e projetos de modernidade pautados naquele período. A forte relação com os discursos e preceitos higiênicos fomentaria a discussão da instrução e da formação de uma civilidade pronta para superar desafios. Assim, nas escolas normais entre 1930 e 1950 os programas articulavam preceitos higiênicos que fomentariam a profissionalização das normalistas na sua atuação e prática de ensino. Portanto, no

“Art. 130. Se ensinará a ensinar (...) o estudo de Hygiene escolar, afim de dar ao futuro professor o conhecimento profundo da creança, fazendo-o compreender praticamente que o 'ensino deverá ser feito para o menino e não este para o ensino."

O que pôde então significar para esse(a) aluno(a) os conhecimentos adquiridos, na verdade, no depoimento do professor Dr. Péricles Ramos ${ }^{1}$, expressou a concepção de higiene trabalhada na escola, voltada para a infância, voltada para o exercício prático do cuidado para com os bebês. Nas palavras do Dr. Péricles,

"Bem, a higiene, desde, desde o nascimento. Todo o cuidado com a criança, todo o cuidado com os utensílios de criança: chucer, mamadeira.

Eu não condenava totalmente o bico, mas eu preciso que tivesse um cuidado muito grande, pois qualquer coisa ele solta, cai, ou, ou, roça mesmo o corpo, de maneira que tudo isso... E, e o banho, como era feito, a água, o calor de água, não sabe? De maneira que ele, desde que criança nasce até ficam mais grandinho.”

Esses conhecimentos que as normalistas eram submetidas consolidou-se a partir do uso de diferentes materiais. O boneco por exemplo, que o Dr. Péricles cita na declaração, faz-

\footnotetext{
${ }^{1}$ Entrevista realizada com o último professor vivo da antiga ENRFSA, o médico pediatra Péricles Rocha Ramos, na década de 1990 por Ione Sousa enquanto doutoranda.
} 
se presente em sala de aula. Segundo ele, não tinham materiais suficientes para todas as alunas, mas utilizaram um boneco como representação infantil para as demais alunas. Esse aspecto demostrou como o treinamento e a aquisição das práticas domésticas, sobretudo do ser mãe, nortearam a educação.

Esta transmissão de saber-fazer aponta a concepção que as normalistas seriam educadas para educarem seus lares e a sociedade. Essa prática pôde demostrar o valor que uma boa educação é capaz de, através de seus alunos, invadir e colonizar as famílias, segundo os critérios medico-higiênico (GONDRA, 2003).

Dessa forma, a instituição ENFSA concebeu um lugar de vivências e práticas correlação com outros discursos estabelecidos na sociedade do Estado Novo, de 1937 a 1945, de cunho eugenista e higienista. Há a presença deles na prescrição, ao propor a higiene moral da sociedade, tendo a conduta como objeto (DIWAN, 2007) central para a organização e para “estirpe” e prestígio do país.

\section{CONSIDERAÇÕES FINAIS}

O presente trabalho, tendo apresentado brevemente as relações entre poderes, discursos, práticas escolares a partir do regulamento da entrevista com o professor da Escola Normal da década de 1940, apresentou também a formação das normalistas vinculadas às disciplinas Hygiene e Puericultura, sendo estas, com o conhecimento proposto, levar a civilidade a irradiação das concepções de civilidade aos mais diferentes espaços, sobretudo, ao sertão atrasado.

Tendo como matriz estas disciplinas, a finalidade educacional em relação às mães e/ou às professoras na primeira metade do século XX, era de cumprir o projeto de nação e do cuidado com o corpo, necessariamente da criança, para a proteção do Estado (DIWAN, 2007). Assim, os batalhões de professoras e mães encarregou-se de civilizar, higienizar e uniformizar os seres do sertão atrasado e carentes da modernização, sendo elas também, atuantes na educação higiênica da sociedade.

\section{REFERÊNCIAS}

CHERVEL, A. História das disciplinas escolares: reflexões sobre um campo de pesquisa. Teoria \& Educação, Porto Alegre, v. 2, p. 177- 229, 1990.

DIWAN, Pietra. Raça Pura: uma história da eugenia no Brasil e no mundo. SP. Contexto, 2007.

FARIA FILHO, Luciano Mendes de. República, Trabalho e Educação: A experiência do Instituto João Pinheiro 1909/1934. Bragança Paulista: Editora da Universidade São Francisco, 2001.

FOUCAULT, Michel. A Ordem do Discurso: Aula Inaugural no Collège de France, pronunciada em 2 de dezembro de 1970. Edições Loyola, São Paulo, Brasil. 1996.

GONDRA, José Gonçalves. Homo Hygienicus: educação, higiene e a reivenção do homem. In: Cadernos Cedes, Campinas, V.23, n.59, p. 25-38, abril 2003a .

LOURO, Guacira Lopes. Mulheres na sala de aula. In: DEL PRIORI, Maria (org). $2^{\text {a }}$ ed. História das mulheres no Brasil. $2^{\mathrm{a}}$ ed., São Paulo: Contexto, 1997.

SOUSA, Ione C.J. de. Garotas tricolores, Deusas fardadas: as normalistas em Feira de Santana. Dissertação de Mestrado em História Social. PEPGHS/PUC-SP: 1999.

VEIGA, Cynthia Greive. Historia Politica e Historia da Educação. In: VEIGA \& FONSECA(orgs). História e Historiografia da Educação no Brasil. BH. Ed. Autentica: 2003.

\section{FONTES:}


RAMOS Péricles Rocha. Entrevista. Realizada em Salvador, 01 de Junho de 1998 (Ione Sousa).

TEIXEIRA, Anísio Spínola. O Ensino no Estado da Bahia. Relatório da Diretoria Geral de Ensino. 1924/1928, p.84.

REGULAMENTO DE ENSINO DO ESTADO DA BAHIA, Lei 1.846 de 14 de Agosto de 1925. 